OPEN ACCESS

Edited by:

Canan Blake,

UCL Institute of Education,

United Kingdom

Reviewed by:

Tracy X. P. Zou,

The University of Hong Kong,

Hong Kong

Jon Mason,

Charles Darwin University, Australia

*Correspondence:

Eileen Scanlon

eileen.scanlon@open.ac.uk

Stamatina Anastopoulou

stamatina.anastopoulou@open.ac.uk

Specialty section

This article was submitted to

Digital Learning Innovations,

a section of the journal

Frontiers in Education

Received: 27 June 2019

Accepted: 31 October 2019

Published: 27 November 2019

Citation:

Scanlon E, Anastopoulou S, Conole G and Twiner A (2019) Interdisciplinary Working Methods: Reflections Based on Technology-Enhanced Learning

(TEL). Front. Educ. 4:134.

doi: 10.3389/feduc.2019.00134

\section{Interdisciplinary Working Methods: Reflections Based on Technology-Enhanced Learning (TEL)}

\author{
Eileen Scanlon ${ }^{1 *}$, Stamatina Anastopoulou ${ }^{1 *}$, Grainne Conole ${ }^{2}$ and Alison Twiner ${ }^{1}$ \\ ${ }^{1}$ The Open University, Milton Keynes, United Kingdom, ${ }^{2}$ Independent Consultant, Northamptonshire, United Kingdom
}

In this paper, we discuss the nature of interdisciplinarity and, in particular, the ways that interdisciplinary working is enacted in TEL Research. Following a design-based research approach, a common TEL methodological approach, we identified how interdisciplinarity facilitated the research team to address a wicked problem, fostered dialogue between researchers in different disciplines and stakeholders in the research through the lifetime of the project and facilitated the creation of new meanings. Focusing on the Personal Inquiry Project $(\mathrm{PI})$ team, interdisciplinary working methods are explored through examining two boundary objects namely the PI octagon and the concept of scenario, that provide windows of how interdisciplinary understanding evolves through time and among different stakeholders. These boundary objects, even though they had different importance within the project, illustrate the team's emergent and shared understanding while maintaining flexibility through a rapid iterative process. We discuss how a shared understanding was facilitated through active involvement of different disciplinary teams and consensus was built and refined in the light of emerging findings. Interviews with researchers on the project and the Advisory Board and on our own reflections on work practices illustrate key themes, i.e., the salience of boundary objects in the design process, the development of a common language, and the importance of a shared vision. We conclude with a set of requirements for progress in interdisciplinary working and comment on our view of good practice in fostering interdisciplinarity along with an outline of what we see as the remaining challenges.

\footnotetext{
Keywords: technology-enhanced learning, interdisciplinary, boundary objects, requirements for progress in interdisciplinary working, interdisciplinarity
}

\section{INTRODUCTION}

Addressing the challenges of complex situations, such as education and learning at schools or beyond, requires for multiple perspectives to be taken into consideration. Interdisciplinarity has become increasingly important as a means of attempting to address complex, real-world research problems and grand challenges (Davé et al., 2016) which is highlighted by the impact case studies submitted to the 2014 UK Research Excellence Framework (REF) (King's College London Digital Science, 2015). Interdisciplinarity requires researchers from two or more disciplines to bring their approaches and adapt them to form a solution to a new problem.

Technology enhanced learning (TEL) research focuses on facilitating learning and teaching at schools or other settings and the need for interdisciplinary approaches is fundamental due to the 
complexity of the situation and the multiple disciplines involved. Such research projects require collaboration between researchers trained in different disciplines who are engaged with the concrete properties of a situation and the available materials, rather than with an abstract model of how they will behave (Scanlon et al., 2013).

In this paper, we reflect on our experiences and those of our colleagues of working in a specific TEL research project the Personal Inquiry Project (PI) team, a project funded by the joint research councils' programme on Technology Enhanced Learning, which was conducted by the Open University and University of Nottingham. Following a design-based research approach, during this project, we developed evidence-based claims derived from experiences in situ that resulted in the production of technological tools, theoretical frameworks, and pedagogical approaches which advanced our understanding of inquiry learning supported by technology (Sharples et al., 2015). Reflecting on our working practices during the Personal Inquiry Project (PI), we explore interdisciplinary research and document the challenges and benefits of interdisciplinary work. Based on interviews with colleagues, as well as project documents e.g., agendas, minutes, and internal papers (kept in our servers), we reveal our working methods, how research is carried out and documented, aiming to take forward the collective understanding of TEL and ways in which new knowledge is developed in these settings. We reflect on two boundary objects, namely the PI octagon and the concept of scenario, that provide windows on how interdisciplinary understanding evolves through time and across different stakeholders. We discuss a set of requirements for progress in interdisciplinary working and comment on our view of good practice in fostering interdisciplinarity along with an outline of what we see as the remaining challenges.

\section{THE NATURE OF INTERDISCIPLINARITY}

Interdisciplinarity derives from a selection of ideas, approaches, theories, concepts, methods and comparisons from different fields or disciplines. These choices, whether successful or not, influence central decisions and problems. In no way does interdisciplinarity depend on the knowledge of entire disciplines or on global notions of the unity of knowledge. There is no single path to interdisciplinarity, no single model, no single standard for successful development (Graff, 2015).

It is often assumed that by synthesizing perspectives, interdisciplinary research should be a group process; however, even though perspectives are drawn from different disciplines and various stakeholders, each contributor does not necessarily have to be involved in bringing the knowledge together (Bammer, 2013, p. 49). People can participate as informants or as active contributors with a varying role adopted by the research leader (final owner of decision-making or collaborative decision-making).

A key challenge for interdisciplinary research is to find ways to improve the knowledge synthesis successfully while maintaining flexibility during the research. Whether attempts to integrate different perspectives are happening at the beginning or toward the end of the research is an example situation. Think, for example, of the production of a book, with different chapters written by different discipline experts, with the synthesis left to the reader. On the other hand, getting agreement on a problem definition, along with the contributions of the different disciplines and stakeholders, at the beginning of the book writing is another way to improve knowledge synthesis, with synthesis being much more straightforward but less flexible (Bammer, 2013, p. 21).

Interdisciplinary research opens up the potential for the development of new theoretical insights and methodological innovations, by bringing different discipline perspectives together to address a particular research problem. This is the result of disciplinary elements, e.g., ideas, methods, and theories, being interactive not additive (Graff, 2015) in the sense that they are subject to negotiation and creative adaptations based on the needs of the particular context. The strengths of bringing different discipline perspectives to bear on a research problem, exposing researchers to alternative research approaches, literatures and methodologies, all provide opportunities for researchers to develop shared understanding and adopt more reflective approaches to research practice.

The purpose of interdisciplinarity is therefore to foster dialogue between researchers in different disciplines and stakeholders in the research with the effect of creating new meanings and/or understandings. Such process can be facilitated by objects, words or diagrams that allow different researchers to work together, even without consensus (see below the key notion of boundary objects (Star, 1988, 2010) which Star defines as organic infrastructures that arise from information or work requirements). We discuss later how we used this concept. Rogers et al. (2005) argue for the need to have a common language so that a shared understanding is developed not only of the background and context of research but also to describe the emerging concepts of the research. A way to represent such shared understanding is through diagrammatic representations, a practice inherited by computer science and philosophy (around theories of $\operatorname{logic}$ ).

\section{Interdisciplinary Collaborations in TEL Research}

Technology Enhanced Learning research requires interdisciplinary collaboration across the disciplines of learning, cognition, artificial intelligence, information and communication technologies in education and broader social sciences (Meltzoff et al., 2009). Researchers are drawn from a broad range of research disciplines, bringing with them a rich set of theoretical perspectives and methodologies. Each project creates opportunities for computer scientists, psychologists, educational technologists, and educational professionals to come together to test out the components of a shared method for developing and evaluating Technology Enhanced Learning, integrating a variety of approaches, e.g., socio-cultural approaches to the understanding of learning (Cobb et al., 2003), and socio-cognitive engineering approaches to the design of technology (Sharples et al., 2002). TEL is a well-established 
interdisciplinary field as demonstrated by funding bodies (e.g., UK-TELRP 2007-2010; FP6, FP7, Horizon 2020), publishers (there are around 20 journals in TEL), and national political agendas internationally. It is also worth noting that it is often used as a synonym for adjacent fields such as e-learning (Friesen, 2009).

Contributory disciplines in TEL work together in order to make progress in understanding learning and to find the ways in which a technology enhanced approach might solve global challenges. To achieve the highest ambitions for education and lifelong learning, TEL researchers need to exploit fully the opportunities new technology and new pedagogies offer for creating more flexible learning opportunities, and integrating innovations in technology and pedagogy, to enhance education, learning and the knowledge building processes. But to do this, a more explicit understanding of the nature of learning is needed, both formal and informal. An explicit understanding is also needed of the way educational practice is responding to changes in society of the opportunities created by new technologies. This understanding supports innovation from both research areas, each challenging the other, aiming to rethink ways of making learning more effective and develop new technology solutions to make that possible. Such interdisciplinary research is intended to help build new understandings of how technology can enhance learning and how learning can benefit from meaningful incorporation of technology.

Apart from collaboration, another important contribution of TEL to ideas around interdisciplinarity focuses on knowledge synthesis and the shared understanding adopted by both researchers of different disciplines and practitioners, e.g., teachers. Each setting, e.g., school, provides different opportunities for interventions so TEL research has a varying degree of flexibility to embed innovative TEL ideas into their practices. Understanding how technologies can be used and how learners and teachers are co-evolving their learning practice by the use of technologies is complex. TEL has the additional purpose of having an impact in real settings, and requires interdisciplinary collaborations where knowledge is created in the context of its application to practical problems. It also raises ethical concerns around the usefulness of the TEL experience in which participants take part. Such concerns relate to the added value that any innovation brings in to the students' experience.

\section{Example of Interdisciplinary Methodology: Design-Based Research}

One of the TEL methodologies that focuses specifically on applying innovative TEL ideas to practice is design-based research (The Design-Based Research Collective, 2003). Instead of simply testing hypotheses, the focus of Design-Based Research (DBR) is on developing a profile or theory that characterizes the design in practice. It allows therefore for flexible design revisions, multiple dependent variables, and captures social interactions. In addition, participants are not "subjects" assigned to treatments but instead are considered as co-participants in both the design and even the analysis (Barab and Squire, 2004). Design-Based Research is a framework of methods used to carry out exploratory research in real settings. It can offer a useful methodological toolkit to those researchers committed to understanding variables within naturalistic contexts. It has been used widely in technology-enhanced learning (Wang and Hannafin, 2005).

Design-Based Research (DBR) reflects the need of tackling wicked problems in an impactful way. Wicked problems have been coined by Rittel and Webber (1973) to shift the attention from a problem solution to a better understanding of a problem itself. They manifested that a purely scientific-engineering approach cannot be applied because of the lack of a clear problem definition and the differing perspectives of multiple stakeholders. Examples of wicked problems include climate change, poverty, energy production, education. A wicked problem has no definitive definition or solutions. Every problem is unique and has no given alternative solution. Due to their significance, there is no opportunity for trial and error, every solution is a one-shot operation. Solutions furthermore are not true or false but can be classified as better or worse (Conklin, 2005).

Wicked problems call for a design thinking approach where researchers collaborate, focus on what they don't know, and navigate a space of incomplete, contradictory, or changing requirements. Due to their complexity, wicked problems demand the input of multiple academic disciplines and stakeholders with relevant practical expertise. Learners, educators, and researchers from multiple disciplines therefore work together to understand the messiness of real-world practice, with context being a core part of the story and not an extraneous variable to be underestimated. Context cannot be described through a single discipline, therefore being aware of interdisciplinary challenges and opportunities make us more apt and flexible to respond successfully.

Within DBR, context is highlighted as being part of the story that is created iteratively, together with participants. Context here is referred to as a description of the learning environment which includes the physical things (i.e., the classroom and the school), the different participants (i.e., learners, teachers, and school leaders) but also the curriculum and its aims. Context is an instance of a wicked problem as it is described through the interactions among stakeholders through multiple iterations of interventions to achieve specific learning objectives. Therefore, DBR is situated in a real educational context, uses mixed methods for data gathering and analysis, involves multiple iterations, and a collaborative partnership between researchers and practitioners, including policy makers, teachers, students, parents (Anderson and Shattuck, 2012). The key, therefore in DBR and wicked problems, is enabling these disparate experts to work together, to ensure that what is developed in the academic lab is grounded in real practice and is challenged by it, something that is critical to address many such wicked problems.

\section{Interdisciplinary Working Practices in Technology-Enhanced Learning}

To help with the difficulties in coordinating planning and communicating in an interdisciplinary project, consensus needs to be developed between project partners on: (1) the research 
questions, (2) methods to be used and evaluation activities which guide the project design, (3) development, and (4) implementation. In particular, the link between the research questions and the methods in which the project stakeholders have experience needs to be established. This is a consensus building activity. However, such consensus needs refining in the light of emerging findings. This translates into active involvement and collaboration of all different disciplinary teams.

Technologies can facilitate active involvement and collaboration. Collaborative technologies play a complex role in mediating the interactions relating to the design of the interventions. A broad range of tools can be used for data storage (shared online spaces), file sharing (e.g., SharePoint) and collective authoring (e.g., Google Docs), and communicative and collaboration tools (e.g., Skype and WhatsApp). Some interactions can take place via mixed mode meetings with some partners attending in person while others participate via a video-link. This has the advantage of enabling flexible working while the experience of the collaborative process is helped by the possibility of reflecting on the persistent digital records created in this way of working. The multiplicity of technologies and the experimental nature of TEL projects, allow researchers to respond creatively to multiple and emergent practices, requirements, and visions across diverse settings (Carmichael and Tscholl, 2013). Practices like rapid prototyping; participatory design; reuse of data; and agile ways of editing, extending, or reconfiguring existing applications have emerged as ways to address the changing requirements from interacting across interdisciplinary teams and real-world settings.

There is also a need for shared understanding across the research teams, e.g., to make a game that could be used to develop the performance of investors, games designers need to understand financial decision-making processes (the context of the game), the characteristics of a financially capable individual (the skills of an expert user), decisions that a trader or investor makes, feedback which needs to incorporate sensor data. Finance experts need to understand the games design process in order to provide the games designers with useful information for games design (Fenton-O'Creevy et al., 2015). Technology can play a part in this. Standard technologies like desktop and laptop PCs and generic computer applications (Word for document creation, Excel for analysis, PowerPoint for story-boarding) as well as more specialized tools related to the individual researcher's area of interest and expertise (e.g., Atlas.ti, Nvivo, Observer, and SPSS) facilitate the development of shared expertise. Working practices that need to be facilitated include researchers moving across sites to collaborate closer with partners as well as to interact with each other's stakeholders. For research teams to develop a shared understanding, there needs to be an abandonment of a simple notion of technology as a container into which data are brought in pursuit of a representation of a singular, if complex, real-world situation (Carmichael and Tscholl, 2013). Not only are technologies being used to support different kinds of cases of interdisciplinary work (from museum studies to policing) but they are sufficiently flexible that they can be used to pose questions about the content, structure, and boundaries of situations in specific instances and across a range of disciplinary and pedagogical practices.

To facilitate further this shared understanding, an agreement on terminology is needed, therefore common language is also very important. The development and application of a common language as a working practice, highlights the breadth of concepts at hand and addresses possible misunderstandings. For example, among psychologists, computer scientists, human computer interaction specialists, educational technologists, education specialists, and practicing teachers, the word "design" is fully understood. Yet, each discipline could offer a different explanation of the term.

When successful, interdisciplinary working practices could also lead to a shared vision between research teams as demonstrated by shared publications, future projects and subsequent job roles. There is no doubt that developing this shared vision needs time as well as a reflective approach from stakeholders, users, and researchers.

\section{Moving Across Disciplines: Mediating Artifacts and Boundary Objects}

When researchers from across a broad range of disciplines are drawn together, they bring a rich variety of theoretical perspectives and methodologies with the potential to provide real insights into some of the challenging research questions in contemporary educational technology. Boundary objects can help us understand what bridging mechanisms can be developed to help teams work across disciplinary boundaries. Boundary objects are arrangements that allow different groups to work together, even without consensus (Star, 2010). They can be technological tools, concepts or a set of ideas, i.e., a diagram or the use of a tool. They are therefore useful constructs since they provide the means to talk about conflicts and the ways to resolve them within and across teams. They highlight and help to coordinate the different perspectives of participants aiming for the development and maintenance of coherence across intersecting social worlds (Star and Griesemer, 1989). They have been the focus of attention in many sociological studies, especially those focusing on the ecology of a workplace and the mediation of knowledge. Bearing in mind the diversity in interdisciplinary research (also in TEL), boundaries, boundarycrossing and boundary objects exemplify the ways by which people try to make sense of upcoming experiences and situations. Boundary objects and boundary crossing carry learning potential (Akkerman and Bakker, 2011) through which knowledge is transformed and collective learning is achieved (Carlile, 2004). We regard interdisciplinarity as the cognitive processes involved around disciplinary crossing of boundaries. We use therefore boundary objects as key concepts to describe the methods of interdisciplinary working.

Mediating artifacts on the other hand provide opportunities for better understanding, articulation and process of discourse (Conole, 2008, 2013). They may be more useful in novel situations where the intended outcomes are not yet clear. The concept of a mediating artifact (e.g., instruments, signs, procedures, machines, methods, laws, and forms of work 
organization) has been incorporated by many researchers within a sociocultural framework-drawing on Vygotsky's notion of "tool" use in building knowledge and sharing understandings. Any physical object, conceptual idea or statement could be considered in this way, but it is how such an artifact is taken up in interaction that allows it to be considered as a mediating artifact. Thus, from a sociocultural stance, researchers reinforce "the need to view any mediational means as a situated and interactional device, which could be employed in different ways by different users and on different occasions (e.g., Wertsch and Tulviste, 1992). Thus, only through action are artifacts given meaning and inspire meaning-making activity" (Twiner, 2011).

When mediating artifacts are used across different contexts, e.g., disciplines or environments, they can represent new shared conceptions of activity and thus encourage and support new learning (Kuutti, 1996). Mediating artifacts are created and transformed during the development of an activity and carry with them a particular culture-a historical residue of that development. Leadbetter (2004) for example discusses how conversations between educational psychologists and teachers are influenced by the mediating artifacts that are used.

Taking these two concepts together-boundary objects and mediating artifacts-we argue that a boundary object can also be considered as a mediating artifact: where an object not centrally familiar to all parties is used to focus discussion and identify differences in interpretation, which can then be negotiated in order to reach consensus of shared interpretation or agree difference. However, we consider that these two concepts are not interchangeable, as a mediating artifact would not always be a boundary object. For instance if there is a tool that is familiar to all participants and so not considered on the "boundaries" of disciplinary expertise, but that can be used to focus attention, consolidate understanding, and define contexts of use, it would be employed as a mediating artifact, but it would not be appropriate to refer to it as a boundary object.

Since developing a shared vision needs time and a reflective approach, the development of boundary objects and mediating artifacts provide windows of how interdisciplinary understanding evolves through time and across different stakeholders. Therefore, the next section describes the evolution of the Personal Inquiry framework or "the octagon" (as it was later referred to) as a boundary object and how it was shaped and appropriated by the different stakeholders of the project. It then discusses the concept of scenario that for a period in the project became the focus of the full research team only to realize the different meanings that it held for different team members. It became a concept to facilitate boundary crossing at a micro-level allowing each member of the team to understand the disciplinary needs of each researcher.

\section{The Personal Inquiry (PI) Project and Its Framework: The Octagon as a Shared Representation}

The Personal Inquiry project aimed to support learning through a method of scripted inquiry that was personally meaningful. It investigated how technologies can be effectively used to enable inquiry learning and, in particular, how mobile technology offers the possibility of supporting evidence-based inquiry learning across formal (classroom) and informal (home and outdoors) settings (Sharples et al., 2015).

During the first year of the project, research focused on theorizing, designing and evaluating personal inquiry learning. A cross project team from the Open University and the University of Nottingham was formed to pursue a literature review to capture the state of the art of the inquiry-based learning literature. This literature review soon became an instrument to shape the theory of what the project aimed to achieve by specifying the theoretical framework for personal inquiry learning. Existing models and frameworks previously used in inquiry learning research were reviewed and the key features and phases of inquiry-based learning were distilled to produce an initial version of the framework (Scanlon et al., 2011).

In parallel to the literature review, the Nottingham team decided to run a pilot study to test how various ideas of inquiry could be enacted in the specific school context. For example, through the literature review, it became clear that inquiry learning is not going to be achieved through an hourlong intervention in a school class as would often be the case with TEL interventions. It was agreed among the teachers and the research team that it would involve around four or more science class hours across a period of a month. During the pilot study, a recurring challenge was that pupils on each day did not know what to do next or how previous activities fed into current ones (Anastopoulou et al., 2008). To address this challenge, the research team decided to use the same construct, the PI framework, to facilitate students' activities through the inquiry process.

At the same time, the Open University team ran focus groups with teachers and project partners, as well as a specific design workshop with pupils, in preparation for their first trial with featured inquiries in geography. During those design workshops, different versions of the PI framework were discussed. The different parts of the framework were also discussed in a number of formats and in workshops among researchers and stakeholders, e.g., project meetings, stakeholder panels across sites (UoN and OU), and the advisory panel. These workshops together with their experience of a pilot study in a different school setting informed the PI framework. The methods adopted during this PI project involved researchers and teachers co-designing interventions with a sequence of inquiries in schools conducted with approval from the Universities ethics approval committee. Data collected included interview data, observations of activities within the classroom and beyond, and students' working notes and final reports on their inquiries.

Essentially the framework developed to guide this work consisted of a number of phases of the inquiry process which need to be supported. Figures 1, 2 show intermediate versions of the representation developed and tested in the design workshops before settling on the representation shown in Figure 3. In Figure 3, the inquiry process is shown to have a number of ways of proceeding, either cycling through all eight stages, or proceeding in a different order or with fewer components (captured in the diagram by dotted lines). 


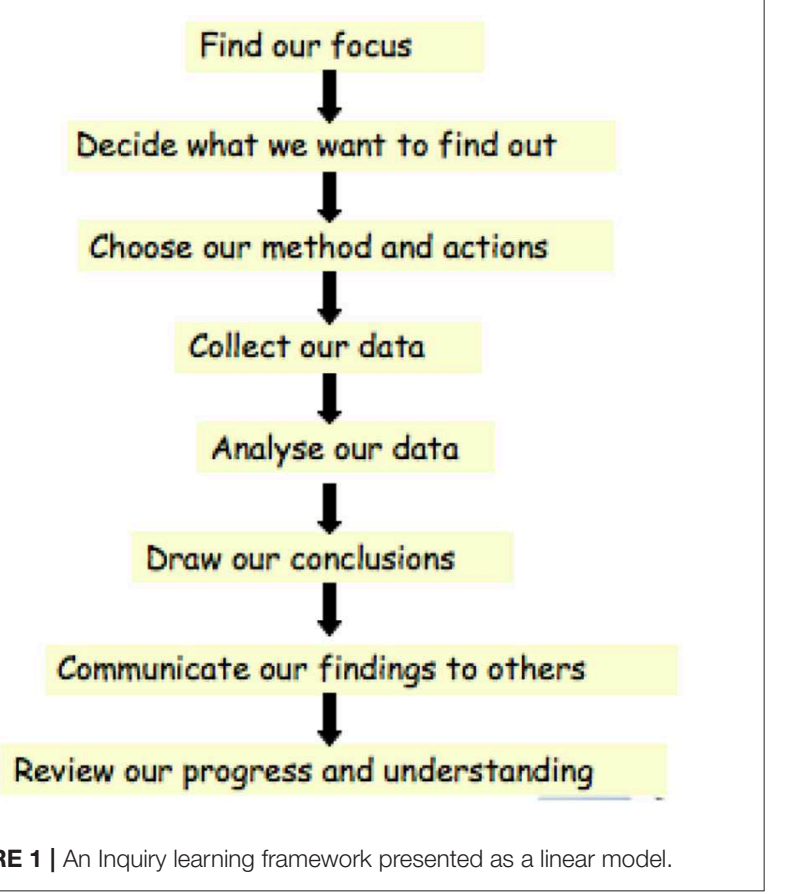

FIGURE 1 | An Inquiry learning framework presented as a linear model.

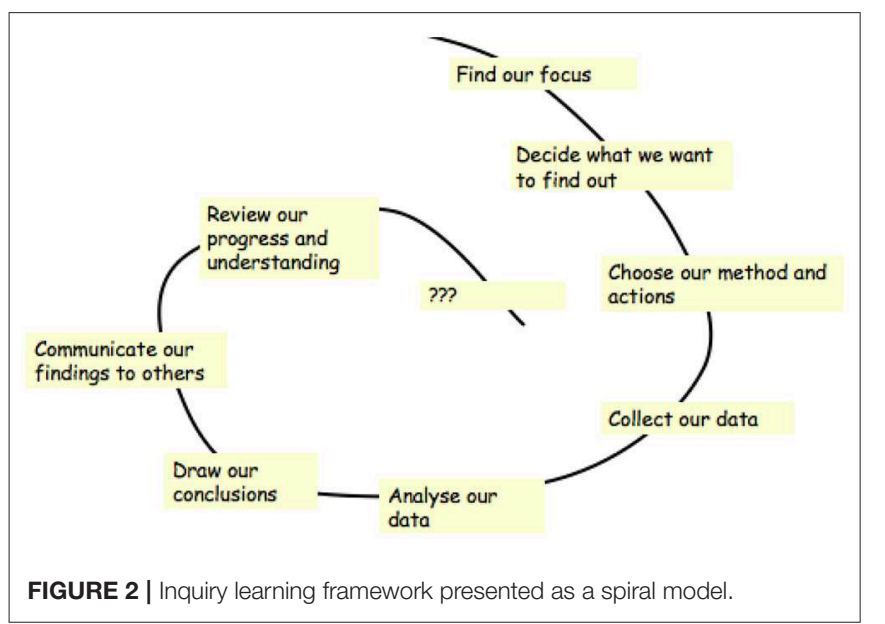

It therefore provided a scaffolding for guiding the learner through the key activities needed in an inquiry-based approach. During those workshops, the PI framework became the boundary object which allowed the different stakeholders to articulate their needs, expectations and hopes to each other. It was flexible enough to accommodate different versions, instantiations or representations, bridging the different perspectives of stakeholders, and was subject to negotiation.

During the first year, the framework was under development and had not yet been fully decided on nor implemented. At these early stages, the framework was a result of synthesis of work arising from the consideration of the literature, the two research teams and the diverse population of our stakeholders. It developed according to the emerging shared understanding of the researchers, following the iterative perspective of Design-Based
Research. It began with defining the focus of the inquiry, moving through data collection and analysis and finally conclusions and reflection. The representation shape as well as the terminology used to describe each phrase were important features. The different representations of the PI framework incorporated key features of inquiry highlighted in past research together with our own early research insights. It incorporated our challenges in implementing inquiry across contexts e.g., flexible coordination of activities, availability of resources, and forms of ownership, which have informed our various representations of the personal inquiry framework. The framework therefore acted as a boundary object which helped guiding the design decisions occurring during participatory design workshops, and the construction of the technological toolkit (Scanlon and Conole, 2018).

As a boundary object, therefore, the PI framework brought forward its learning potential which included new understandings, identity development, change of practices, and institutional development (Akkerman and Bakker, 2011). Following Akkerman's and Bakker's categorization, the PI framework as a boundary object aimed to (1) identify and appropriate the language to shape the inquiry activities in the classroom and beyond (identification), (2) explore the sequence of activities (coordination), (3) provide a space to reflect on research and teaching practices (reflection), and (4) recognize the shared problem space and provide hybrids structures of inquiry learning (transformation). Through multiple design workshops, it allowed us to work collaboratively at the boundaries of different disciplines, in a continuous endeavor of joint working.

During the second year of the project, elements of the PI toolkit were implemented. Based on the findings of the first year, the toolkit has now a "Dynamic ToDo List" (Figure 5) that can display a personal inquiry plan, giving a broad overview of the whole inquiry process that unfolds into a hierarchy of necessary and optional activities. The aim is for students not only to visualize where each activity fits into the inquiry, as a whole, but also to appreciate how current actions can influence future ones (Anastopoulou et al., 2008).

The Nottingham team produced detailed lesson plans and online activities in partnership with the teacher. To facilitate pupils' memory around the transition from one science class to the next, a poster was introduced by the teacher to the class. It was one of the ideas that the researchers suggested to the teacher that she was happy to incorporate into her activities. The poster (Figure 4) was auxiliary, a last-minute creative addition to the lessons plans already developed. Its orientation was rather linear, following the initial conceptualization of the research team at the time, but with clear transitions between the different inquiry phases.

The PI framework underpinned the design of the project's technology (PI toolkit, see Mulholland et al., 2012) and acted as a scaffold not only for the structure of the lesson plans but also for the relevant thought processes and activities in the inquiry process. Dynamic To-Do list as was featured on the software under development at the same time (Figure 5) as the poster, referred to as the inquiry guide, supported the classroom physical interactions. 


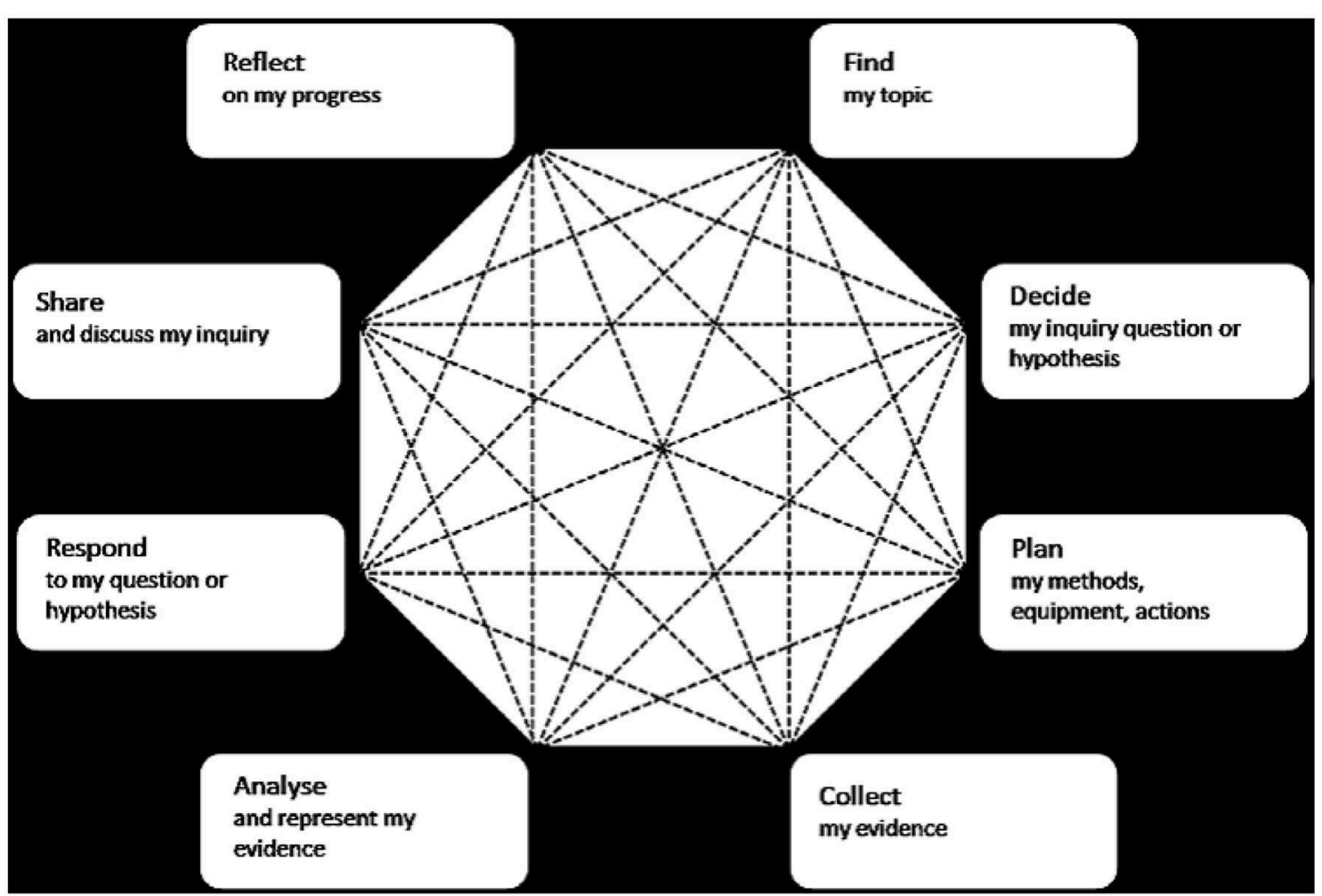

FIGURE 3 | A representation of an Inquiry Learning framework- one of the mediating artifacts and boundary objects used during the personal inquiry project (see also in Sharples et al., 2015, p. 314).

At the beginning of the third year (November 2009), the personal inquiry framework had evolved (Figure 6) and formed a more substantial role in teachers' understanding and the lessons plans. In parallel, the poster had become bigger, rather circular without clear arrows nor clear transitions from one phase to the next (Figure 7).

Ultimately, when the various Personal Inquiry trials had finished, the teacher in Nottingham utilized her experience to generate a permanent poster for her science class. It provided "a useful visual reference," a language to approach her students and at the same time meet the aims of the curriculum. It covered half a wall of the science class and guided the science lessons of the teacher (Figure 8). In her own words:

"I think it'll change my language and maybe that will help them home in more on what exactly they're doing in each phase or each bit of the lesson. Hopefully, that'll maybe make it clear in their minds."

This example highlights how the PI octagon lead to profound changes in the practices not only of researchers but also of the teacher. The octagon, as a boundary object, was transformed to the specific context of the teacher to create a new practice that she owned. It therefore became an object of her own practice/discipline, mediated her practice, and provided the structure she required.
Following a DBR approach in developing technologyenhanced learning tools, therefore, the PI project and the PI octagon allowed for ample opportunities for researchers and practitioners to work together, to develop new pedagogical concepts and technologies through multiple iterations that were embedded in two different contexts allowing for individual needs and differences to be met. As it is prominent by its many publications, the project therefore tackled a wicked problem and developed theories for personal inquiry that characterized the design in practice (e.g., Scanlon et al., 2011).

\section{The Concept of Scenario as an Example of Developing a Shared Understanding}

As mentioned earlier, the PI project was interdisciplinary, integrating into a team, members of the key disciplines of Education, Computing, and Psychology. The approach of codesign of technology and pedagogy involved interdisciplinary discussions and agreement on key methods and concepts, such as "scenario" and "scripted inquiry," such that they can be interpreted by Education researchers (to develop a model of inquiry learning and guide the development of lesson plans), by Computer Scientists (to inform the design of the Inquiry Toolkit) and Psychologists (to enable the design of suitable instruments for evaluation of personal inquiry learning across formal and informal settings). The research method and data collected involved notes of meetings and design decisions, supplemented 


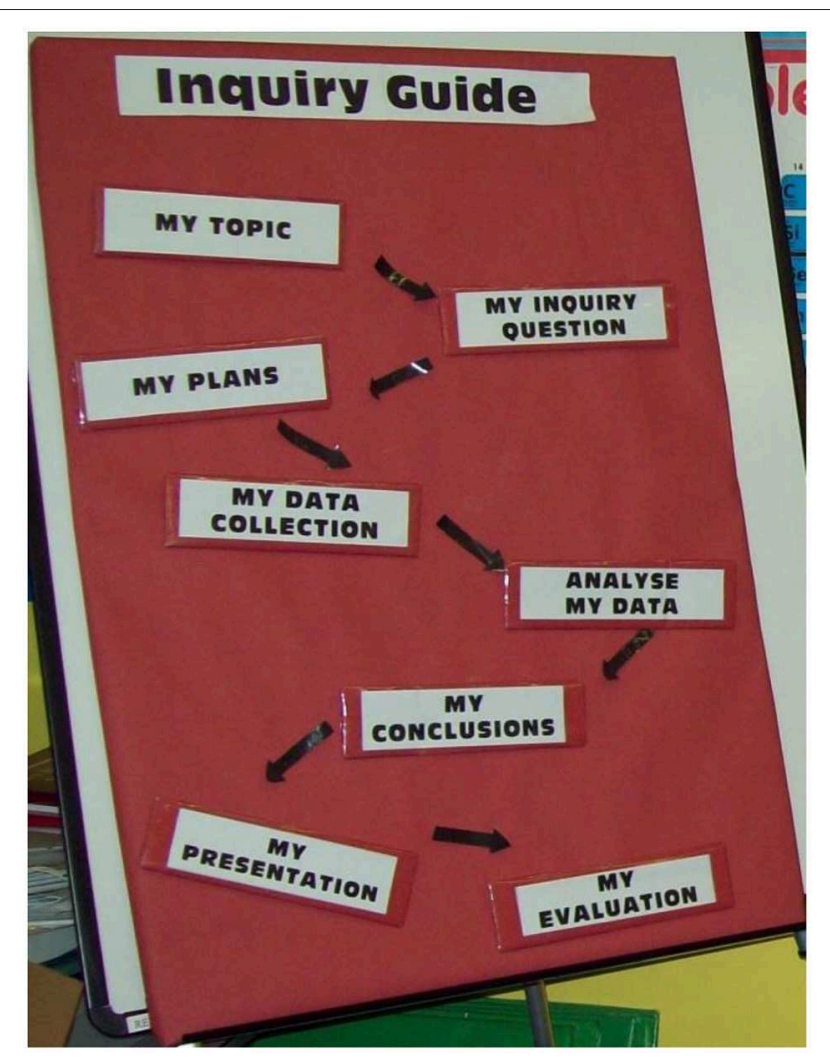

FIGURE 4 | The Inquiry Guide as presented in the Nottingham class in 2008.

by individual interviews conducted by a new member of the team asking team members to reflect on the progress of the project. Focusing on the concept of "scenario" as another boundary object, we highlight how many different interpretations this word could refer to within the people involved.

During the first year of the project, it became apparent that the different teams and different researchers within each team (who came from different departments and schools within each university) had different interests and priorities. How these interests were going to influence the progress of the project was negotiated through meetings, decisions and reports. For example, some researchers required a set of representations to guide the development of user-computer interactions. Other researchers were expecting different formalisms to be generated to express the different narratives that each trial would offer. There was also a need to refine the requirements to be fulfilled by technology and those to be fulfilled by pedagogy. Would a scenario be a narrative, a user story, a lesson plan or a fictional story to facilitate evaluation? These are examples of the different meanings members of the team brought into their interpretation of the word "scenario." The different understandings of "scenario" were not made explicit at the start-so individuals and teams held different conceptions not only of the meaning of the term, but also how it would be enacted through the TEL system.

Since the development of a common language was part of the first aims of the project in developing ways of working, the

\section{Inquiry Guide Healthy Eating}

My Topic

My Topic Summary

My Inquiry Question

国 My Inquiry Questions Are

My Plans

Interview Plan

Photo Diary Plan

圈My Plans Summary

My Data Collection

DInterview Answers

Further Interview

Question

DUpload Photos

$\square$ Food Diary

Problems With Data

Collection

DData Collection Summary

Analyse My Data

My Conclusions

FIGURE 5 | Part of the PI toolkit used in the 2008 trials, before the octagon was fully conceived and implemented.

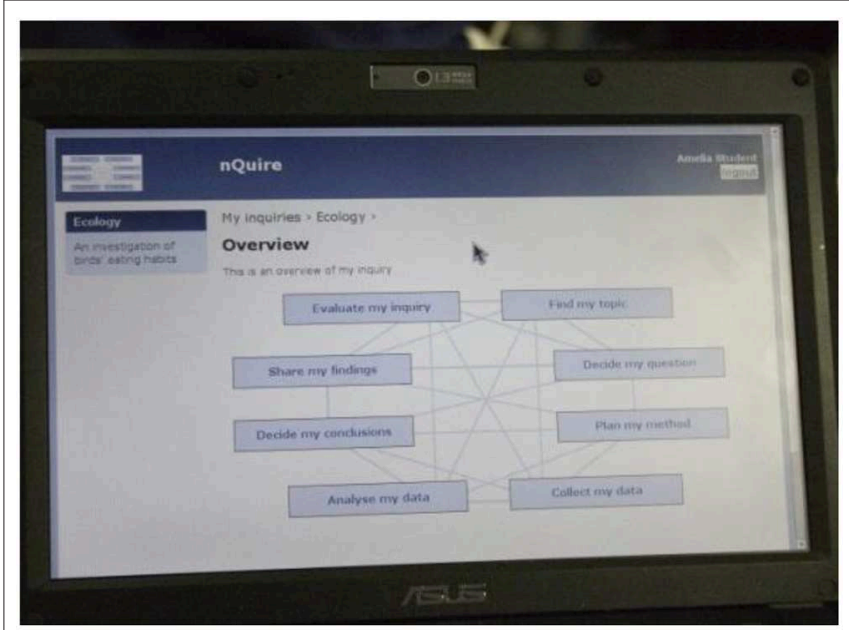

FIGURE 6 | The personal inquiry toolkit (PI toolkit, or nQuire) when used in the trials of the third year.

different meanings of the "scenario" term were surfaced early in the life of the project. The first version of the project "glossary wiki” was produced during a workshop event, when different 


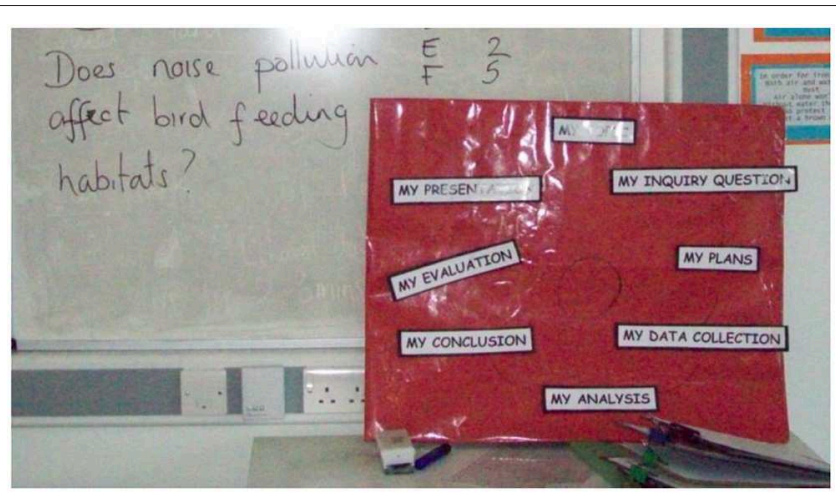

FIGURE 7 | The poster for inquiry learning presented in the Nottingham class in 2009 .

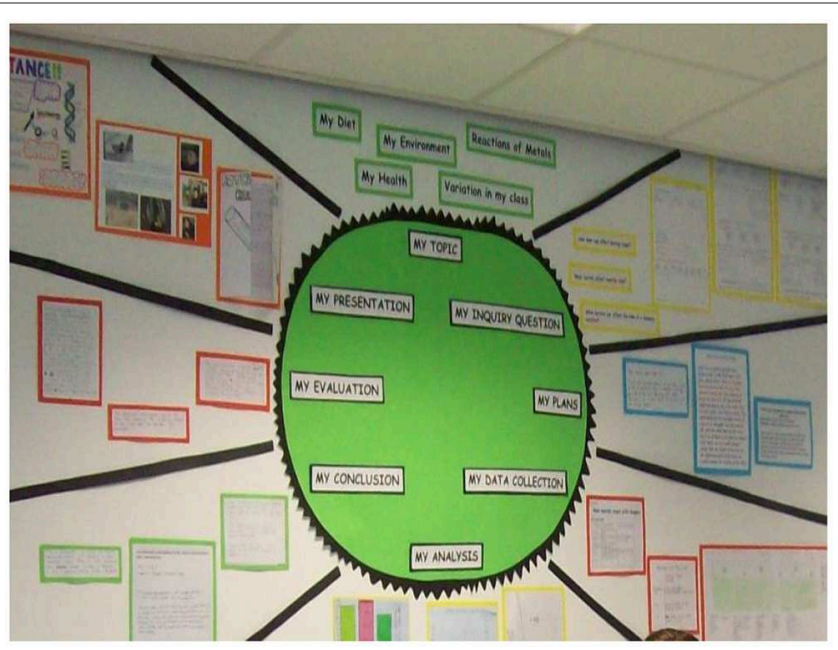

FIGURE 8 | Personal Inquiry poster created by the teacher in Nottingham (2010). It lived long after the PI project had finished (it is reproduced from Sharples et al., 2015, p. 330)

members of both teams had been asked to work together to generate a "scenario." What was produced was a set of different descriptions, in different levels of granularity, some visionary, and some less so. As a result, the term "scenario" was subject to negotiation so that people could have a shared understanding and manage expectations. One of the team members highlights this as follows by talking about the importance for the project of:

"getting a shared vocabulary, or not even a shared vocabulary but a way of translating between technical and the education. The classic example was that we'd been using 'scenario' differently, the central term in the project. And on the face of it very simplistic. But [we] had a nervousness that something was wrong. And actually it turned out to be relatively simple in that you've got educational scenarios and you've got HCI scenarios. And they are quite distinct: HCI, visionary, this is what it might be; and educational is almost a description of the setting. So I think that was quite a major breakthrough in terms of a shared language between those two." [INT 120808]
The term "scenario" therefore became a boundary object with significant learning potential. Following (Akkerman and Bakker, 2011) categorization, the term "scenario" as a boundary object aimed to identify processes by defining one research discipline in light of the other, delineating how it differs from the other discipline (identification). These differences led to a negotiation of different identities, which do not harmoniously co-exist; as a result. Finding a balance by translating the ambiguity of the term into a diversity of possible understandings (coordination), and providing a space to reflect on different perspectives so that the team's understanding of the term is enriched (reflection). This boundary object was not useful for enough time to facilitate transformation of researchers' practices. It was rather helpful to overcome the challenge when working together, and to develop a shared understanding of the needs of the different schools and research teams.

\section{REFLECTIONS}

The two examples of the boundary object described in the previous sections demonstrate the ways in which knowledge development occurred within a particular TEL project. The PI framework or the "octagon," as it was called toward the end of the project, illustrates the team's emergent and shared understanding though a rapid iterative process, following a Design-Based Research methodology (Barab and Squire, 2004). During the project, a number of interviews were conducted about the nature of interdisciplinarity with members of the PI Team and the Advisory Board involved. These interviews illustrated the key themes already emerging from our discussion: the salience of boundary objects in the design process, the development of a common language, and the importance of a shared vision. As one PI researcher reflects on the use of the PI framework within the team:

"I think with any kind of participatory design it's got to be fairly concrete for the people you're working with. I think if it's a [Team] meeting we can talk in the abstract about, you know, there's an inquiry cycle, how might we want to embed in it navigation." [INT 260808]

Through active involvement and collaboration of all different disciplinary teams across both sites, the team negotiated consensus at all times. The term "scenario" as a different boundary object demonstrates the dialogue between researchers and the development of a common language so that a shared understanding is developed not only of the background and context of research but also to describe the emerging concepts of the research. Our awareness of interdisciplinary challenges allowed these discussions to happen early enough in the project. Allowing diversity of possible understandings, the team found a balance by translating the ambiguity of the term "scenario" into something useful for a period of time (Year 1 of the research). The octagon as a boundary object, on the other hand, lived on throughout the life of the project, it changed, and it facilitated the emergent shared understanding and unified the terminology used across the project. When asked about how shared understanding 
during the design process could take place one of the researchers replied using boundary objects as a useful metaphor:

\begin{abstract}
“...boundary objects, or just shared representations, just like a boundary representation, a way in which one group of people can communicate with another group of people. Because for those of us within the project that are maybe doing some of the software or the code, we'll talk about it based on a shared language that we have, for all the technical aspects of it. When it's just between ourselves, that's a really efficient way to discuss it, and we can talk about ideas very quickly that way. But it doesn't work with other people. You know with the teachers, that approach isn't appropriate, you have to really change your language and how you describe stuff. And even then you're often describing things in terms of what they're similar to. So we might say it's a bit like Google maps, which they'll kind of understand what you mean roughly, but they won't actually understand specifically until you say it's like this screen. So those [screens] and the physical illustrations [inquiry diagram] are really key part to getting that." [INT 180808]
\end{abstract}

We coped with the challenges of interdisciplinary working through reflective approaches to research practice. By addressing initial differences in understanding between the disciplines, interdisciplinarity awareness forced us to address those challenges early enough and find ways to overcome them in order for the research to proceed. The results not only informed the development of the learning materials, toolkit, and evaluation methods but also transformed them in parallel through rapid iteration of designs for all these elements. In the words of a PI researcher:

"It's the notion that there is something that you design that is a combination of lots of different people's expertise. There's this notion of an artifact that you can focus on and I think that's a very significant part. I mean there are two things, you can't do a TEL project without: lots of multi and inter-disciplinary expertise and a product. You produce something that then needs quite a complicated approach to investigate." [INT 150310]

Our account above of the preparation for conducting initial school trials in 2008 illustrates how we coped with the challenge of interdisciplinary working that required integration and adaptation of existing materials and methods. It proved successful in forging an interdisciplinary approach to design, revealing initial differences in perception and priority between the disciplines that had to be addressed and overcome in order for the trials to proceed. The results not only informed subsequent trials but also provided a shared vision among different researchers and disciplines, different stakeholders, bridging the "boundaries" between theory and practice and the work needed to theorize, design, and evaluate personal inquiry learning. In the words of one of the principal investigators:

"the PI 'octagon' was a key mediating artifact between the OU and UoN teams, as well as between the pedagogy and technical teams." [Interviewee I]

Another researcher reflects on bridging boundaries between theory and practice among different stakeholders: "if you keep three simple stakeholders, us as researchers, there's the teachers, and the learners as the third, and you can divide us as researchers into those who are essentially educationally focussed, and the technical side of things. It's about the shared representation and understanding between those different stakeholders, and what the purpose is." [INT 120808]

\section{CONCLUSION}

This paper focuses on the ways in which interdisciplinary working is enacted in the field of TEL research. Following a Design-Based Research perspective, we identified how interdisciplinarity facilitated the research team to address a wicked problem, fostered dialogue between researchers in different disciplines and stakeholders in the research through the lifetime of the project. We described two boundary objects, namely the PI framework or the "octagon" and the term "scenario," both of which provided ways to improve knowledge synthesis while maintaining flexibility during the research.

Undertaking true interdisciplinary research is challenging and often in reality the collaboration between disciplines is only at a surface level (Conole et al., 2010). The rest of the paper discusses good practices and challenges that could facilitate or impede interdisciplinary collaborations.

\section{Good Practices}

Understanding interdisciplinary working is key to the successful future of TEL research. It is important that as a community we work harder at fostering interdisciplinary working practices and in making it work. It is necessary to provide the time and space for researchers to become encultured into interdisciplinary practices and be rewarded for doing so. There is a need for changes at policy level too, to recognize and reward this type of research (Conole et al., 2010).

Furthermore, researchers will need to develop teaching experience and skills not only relevant to their academic home or birth discipline, but also to support interdisciplinary teaching based on research. Therefore, academics should develop teaching experience in both core and interdisciplinary areas and institutions should show support for interdisciplinary, researchbased teaching and recognize its value in evaluating academic careers (The British Academy, 2016). With interdisciplinary research valuable for addressing practical challenges, there is a potentially growing market for interdisciplinary teaching at all levels (Davé et al., 2016).

The working practices developed in the PI project to support active involvement, collaboration and the development of shared understanding were:

- A participatory, iterative and reflective approach to the design and evaluation of pilot studies through allowing time and devoting effort to develop a shared understanding and common vocabulary (e.g., weekly meetings of the full research team, interactions with the core schools, multiple workshops with stakeholder panel and the advisory board).

- Cross-fertilization to produce something new and different from what the teams had produced before. 
- Developing effective communication mechanisms and means of recording shared understanding across the team. Examples are:

a. a shareable wiki glossary of terms eliciting a shared language across our different discipline perspectives. Terms such as "scenario," "task," "stages," "phases," and "workflow" were clarified within the first year of the project. We have focussed here on "scenario" as an example.

b. Adoption of agreed representations to support the design of the educational scenarios we were developing and evaluation of their relevance.

c. The different pilot studies in schools were clearly articulated and shared with the research team during their enactment not afterwards, so that emergent opportunities and challenges could be discussed and acted upon through an interdisciplinary lens.

- Build up a community between the researchers, aiming to establish lasting working relationships with people never worked with before.

We don't present these as a set of prescriptions for good practice for all interdisciplinary projects rather as a set of experiences of working within an interdisciplinary project which we found we needed to adopt to make progress.

\section{Challenges}

Regardless of the efforts of some researchers to promote interdisciplinary practices and collaborations, achieving a good solution to a wicked problem is complex. Employing newly developed prototypes, for example, in schools with real students and teachers requires confidence and flexibility by both the teachers and the researchers. Improvisations may be needed to fill in delays or unexpected behaviors from technology. When interventions happen in schools, ultimately the teacher needs to act on the fly, be flexible, and embrace the risk that comes with any innovation. The possible way to support the teacher in this process is through developing a trusting relationship between the school and the research team.

Further tensions between research and practice, relate to the ethical dilemmas of the learning outcome. Even though the aim of any TEL intervention is to enhance the learning experience, when many different innovations are coming together, sometimes things might not go according to plan. Prototypes may crash; designs may not work with many students; students may refuse to participate (openly or not). What is more, if technology is too pervasive, then the wellbeing of students might be at stake. These challenges need to be discussed within the research team as well as with the different stakeholders so that everybody is aware of the risks and the challenges and a plan of actions is agreed.

Focusing on research teams in general, there are challenges in different disciplines working together. Some examples of these challenges (not experienced in the PI project) relate to off the shelf technologies not designed according to pedagogical needs or being too immature to cater for the needs of a classroom. Lesson plans similarly might be too generic to be supported by technology or the evaluator might expect specific measures to have at hand. Within a research project, furthermore, researchers' needs would need to be addressed and research outcomes need to be produced. Therefore, publications may be too abstract to actually express any of the real challenges in this work and too much tacit knowledge can be hidden within a research lab or the mind of researchers.

\section{Final Words}

This rich data set of project experiences has given us valuable insights into the specific challenges of doing TEL research and to the kinds of and nature of knowledge and how it can be co-constructed. In addition, we have shown how the use of purposeful mediating artifacts can help guide this coconstruction process. The boundary objects act at two levels: both in terms of providing a diagrammatic representation of the key insights derived from the literature on inquiry learning and as a dialogic aid to structure and guide discussion within the project. There is no doubt that the interdisciplinary nature of the field is necessary if the grand challenges of the area are to be tackled. As we have illustrated above there are significant challenges in working in interdisciplinary teams and specific strategies need to be put in place to deal with them.

\section{DATA AVAILABILITY STATEMENT}

The datasets generated for this study are available on request to the corresponding author.

\section{ETHICS STATEMENT}

The studies involving human participants were reviewed and approved by Human Research Ethics Committee The Open University. The participants provided their written informed consent to participate in this study.

\section{AUTHOR CONTRIBUTIONS}

All authors have contributed to this manuscript and have substantially contributed to the conception or design of the work. to the drafting the work or revising it critically for important intellectual content. They provide approval for publication of the content and agree to be accountable for all aspects of the work in ensuring that questions related to the accuracy or integrity of any part of the work are appropriately investigated and resolved.

\section{ACKNOWLEDGMENTS}

Our thanks are due to the teachers and students and other stakeholders we have worked with in our investigation of inquiry learning and the ESRC/EPSRC Technology Enhanced Learning Phase of the Teaching and Learning Research Programme for funding the work of the PI project Personal Inquiry: (PI) Designing for evidence-based inquiry Learning Across Formal and Informal Settings (RES-139-25-038) and the investigation of interdisciplinarity. We are also grateful to our colleagues with whom we worked together in the PI project and particularly to Paul Mulholland and Mark Gaved for help with the figures. 


\section{REFERENCES}

Akkerman, S. F., and Bakker, A. (2011). Boundary crossing and boundary objects. Rev. Educ. Res. 81, 132-169. doi: 10.3102/0034654311404435

Anastopoulou, S., Sharples, M., Wright, M., Martin, H., Ainsworth, S., Benford, S., et al. (2008). "Learning 21st century science in context with mobile technologies," in Proceedings of the mLearn 2008 Conference: The Bridge From Text to Context (Wolverhampton: University of Wolverhampton), 12-19.

Anderson, T., and Shattuck, J. (2012). Design-based research: a decade of progress in education research? Educ. Res. 41, 16-25. doi: 10.3102/0013189X11428813

Bammer, G. (2013). Disciplining Interdisciplinarity: Integration and Implementation Sciences for Researching Complex Real-World Problems. Canberra: ANU Press.

Barab, S., and Squire, K. (2004). Design-based research: putting a stake in the ground. J. Learn. Sci. 13, 1-14. doi: 10.1207/s15327809jls1301_1

Carlile, P. R. (2004). Transferring, translating, and transforming: an integrative framework for managing knowledge across boundaries. Organ. Sci. 15, 555-568. doi: 10.1287/orsc. 1040.0094

Carmichael, P., and Tscholl, M. (2013). Cases, simulacra, and semantic web technologies: cases, simulacra, and semantic technologies. J. Comput. Assist. Learn. 29, 31-42. doi: 10.1111/j.1365-2729.2011.00459.x

Cobb, P., Confrey, J., diSessa, A., Lehrer, R., Schauble, L. (2003). Experiments in educational research. Educ. Res. 32, 9-13. doi: 10.3102/0013189X032001009

Conklin, J. (2005). "Wicked problems \& social complexity," in Dialogue Mapping: Building Shared Understanding of Wicked Problems, eds T. Baines, P. Petridis, and K. Ridgway (Wiley).

Conole, G. (2008). "The role of mediating artefacts in learning design," in Handbook of Research on Learning Design and Learning Objects: Issues, Applications and Technologies, eds L. Lockyer, S. Bennett, S. Agostinho, and B. Harper (Hersey, PA: IGI Global), 187-207.

Conole, G. (2013). Designing for Learning in an Open World. New York, NY: Springer.

Conole, G., Scanlon, E., Mundin, P., and Farrow, R. (2010). Interdisciplinary research: Findings From the Technology Enhanced Learning Research Programme (Prepared for the TLRP-TEL Programme) (London).

Davé, A., Hopkins, M., Hutton, J., Krčál, A., Kolarz, P., Martin, B., et al. (2016). Landscape Review of Interdisciplinary Research in the UK. Report to HEFCE and RCUK by Technopolis and the Science Policy Research Unit (SPRU), University of Sussex, 184.

Fenton-O’Creevy, M., Adam, M., Clough, G., Conole, G., Gaved, M., Lins, J. T., et al. (2015). "A game based approach to improve traders' decision making," in The International Gamification for Business Conference 2015: Strategic Industrial Applications of Gamesand Gamification, 21-22 Sep 2015 (Birmingham).

Friesen, N. (2009). Re-thinking e-Learning Research: Foundations, Methods and Practices, Vol. 333. New York, NY; Bern: Peter Lang.

Graff, H. J. (2015). Undisciplining Knowledge: Interdisciplinarity in the Twentieth Century. Baltimore, MD: JHU Press.

King's College London Digital Science (2015). The Nature, Scale and Beneficiaries of Research Impact: An Initial Analysis of Research Excellence Framework (REF) 2014 Impact Case Studies. Bristol: HEFCE.

Kuutti, K. (1996). "Activity theory as a potential framework for humancomputer interaction research," in Conext \& Consciousness: Activity and Human Computer Interaction, ed B. Nardi (Cambridge, MA: MIT Press), 17-44.

Leadbetter, J. (2004). The role of mediating artefacts in the work of educational psychologists during consultative conversations in schools. Educ. Rev. 56, 133-145. doi: 10.1080/0031910410001693227

Meltzoff, A. N., Kuhl, P. K., Movellan, J., and Sejnowski, T. J. (2009). Foundations for a new science of learning. Science 325, 284-288. doi: 10.1126/science. 1175626

Mulholland, P., Anastopoulou, S., Collins, T., Feisst, M., Gaved, M., Kerawalla, L., et al. (2012). nQuire: technological support for personal inquiry learning. IEEE Trans. Learn. Technol. 5, 157-169. doi: 10.1109/TLT.2011.32
Rittel, H. W. J., and Webber, M. M. (1973). Dilemmas in a general theory of planning. Policy Sci. 4, 155-169. doi: 10.1007/BF01405730

Rogers, Y., Scaife, M., and Rizzo, F. (2005). "Interdisciplinarity: an emergent or engineered process?” in Interdisciplinary Collaboration, eds S. J. Derry, C. D. Schunn, and M. A. Gernsbacher (Mahwah, NJ: LEA), 24-46.

Scanlon, E., Anastopoulou, S., Kerawalla, L., and Mulholland, P. (2011). How technology resources can be used to represent personal inquiry and support students' understanding of it across contexts: Technology resources and personal inquiry. J. Comput. Assist. Learn. 27, 516-529. doi: 10.1111/j.1365-2729.2011.00414.x

Scanlon, E., and Conole, G. (2018). Interdisciplinarity in technology enhanced learning: an interview study. J. Interact. Media Educ. 1, 1-8. doi: 10.5334/jime.476

Scanlon, E., Sharples, M., Fenton-O'Creevy, M., Fleck, J., Cooban, C., Ferguson, R., et al. (2013). Beyond Prototypes: Enabling Innovation in Technology Enhanced Learning. Milton Keynes: Open University.

Sharples, M., Jeffery, N., du Boulay, J. B. H., Teather, D., Teather, B., and du Boulay, G. H. (2002). Socio-cognitive engineering: a methodology for the design of human-centred technology. Eur. J. Operat. Res. 136, 310-323. doi: 10.1016/S0377-2217(01)00118-7

Sharples, M., Scanlon, E., Ainsworth, S., Anastopoulou, S., Collins, T., Crook, C., et al. (2015). Personal inquiry: orchestrating science investigations within and beyond the classroom. J. Learn. Sci. 24, 308-341. doi: $10.1080 / 10508406.2014 .944642$

Star, S. L. (1988). "The structure of ill-structured solutions: boundary objects and heterogeneous distributed problem solving," in Readings in Distributed Artificial Intelligence, eds M. Huhns and L. Gasser (Menlo Park, CA: Kaufman), 37-54.

Star, S. L. (2010). This is not a boundary object: reflections on the origin of a concept. Sci. Technol. Hum. Values 35, 601-617. doi: $10.1177 / 0162243910377624$

Star, S. L., and Griesemer, J. (1989). Institutional ecology, 'translations' and boundary objects: amateurs and professionals in Berkeley's Museum of vertebrate zoology. Soc. Stud. Sci. 19, 387-420. doi: $10.1177 / 030631289019003001$

The British Academy (2016). Crossing Paths: Interdiscipinary Institutions,Careers,Education and Applications. Available online at: http:// thebritishacademy.ac.uk

The Design-Based Research Collective (2003). Design-based research: an emerging paradigm for educational inquiry. Educ. Res. 32, 5-8. doi: 10.3102/0013189X032001005

Twiner, A. (2011). Sociocultural understandings of technology-mediated educational practices: improvable objects and meaning-making trajectories in the ICT-literate classroom (Ph.D. thesis). The Open University, United Kingdom; Milton Keynes.

Wang, F., and Hannafin, M. J. (2005). Design based research and technologyenhanced learning environments. Educ. Technol. Res. Dev. 53:5. doi: 10.1007/BF02504682

Wertsch, J. V., and Tulviste, P. (1992). L. S. Vygotsky and contemporary developmental psychology. Dev. Psychol. 28, 548-557. doi: $10.1037 / 0012-1649.28 .4 .548$

Conflict of Interest: The authors declare that the research was conducted in the absence of any commercial or financial relationships that could be construed as a potential conflict of interest.

Copyright $(2019$ Scanlon, Anastopoulou, Conole and Twiner. This is an open-access article distributed under the terms of the Creative Commons Attribution License (CC $B Y)$. The use, distribution or reproduction in other forums is permitted, provided the original author(s) and the copyright owner(s) are credited and that the original publication in this journal is cited, in accordance with accepted academic practice. No use, distribution or reproduction is permitted which does not comply with these terms. 